\title{
Fragmentos de una conversación con Ana María Amado
}

Sandra Carli

Dicen que a veces hay que irse del lugar del origen para

aprender algunas cosas

y que de esto el santiagueño algo sabe.

A mí me ha tocado darme unos cuantos cabezazos

aquí nomás, en Tucumán

hasta que he vuelto

he traído la vena de la escritura abierta

Andrés Navarro

"Historia universal de Santiago del Estero"

Como parte de un proyecto de investigación ${ }^{1}$ sobre itinerarios biográficos y académicos de profesores y profesoras del campo de Humanidades y Ciencias Sociales le hice una entrevista a Ana Amado en el mes de octubre de 2014. La conocía a través de personas cercanas pero no había tenido mayor contacto con ella. Había leído Lazos de familia, libro escrito con Nora Domínguez, y me había encontrado a sugerencia suya con una becaria que dirigía, que investigaba sobre historia de la infancia y viajaba a Estados Unidos. Cuando busqué información en Internet sobre Ana, me sorprendí. La suponía opacada por Nicolás Casullo, su compañero, prejuicio androcéntrico. Me encontré, en cambio, con un recorrido muy personal: una foto con otras profesoras de Filosofía y Letras en un evento festivo con el trasfondo de un edificio antiguo. Me había encantado: tenía un brillo y una sonrisa especiales. 
Costó concertar la entrevista por los tiempos ajetreados de la vida académica. A propuesta de Ana, nos encontramos en un bar ubicado en Av. Córdoba y Sánchez de Bustamante, La esmeralda. Imaginé que sería un lugar más típico de Buenos Aires, quizás por el nombre, o pensando en el bar El Británico, del que era habitué Nicolás. Pero era un bar-pizzería. Llegó con su campera inflable, liviana, como las que se usan ahora, con gorrito de lana porque, según me comentó, había estado enferma. Pensé entonces en su aspecto moderno y lo asocié con los pantalones oxford de Susana Checa, a quien había entrevistado también, amiga, a su vez, de Ana. Son los sixties, pensé.

La conversación se extendió más de dos horas; en mis notas de entonces escribí que tenía que volver a entrevistarla para ahondar en algunos temas, en particular en su contacto con Estados Unidos y en sus temas y proyectos actuales. No lo hice. El año pasado me enteré de su fallecimiento. Cuando se producen estas dolorosas muertes, esas conversaciones guardadas provocan inquietud.
Cuando le envié por mail a Ana la entrevista desgrabada y le comenté que, en caso de poder publicarla, la revisaría con ella, escribió: "es imprescindible la edición, porque fui bastante errática en las referencias, me pasa cuando hago memoria en general". Comparto en este sentido algo que señala Daniel Link en un texto en el que la recuerda:" "El estilo hablado de Ana, que puede todavía apreciarse en algún video de Internet, era entrecortado porque cuando uno le hacía una pregunta ella realmente escuchaba y trataba de pensar la mejor respuesta (no para ella, sino para su interlocutor)". Voy a intentar recuperar fragmentos de aquella conversación, tratando de dar cuenta de ese estilo entrecortado, que se vincula con su oficio inicial de periodista (la periodista entrevistada), y de recorrer su itinerario biográfico y académico. Para ello, he contado con la colaboración de sus hijas, hermanos, hermanas y amigos para responder algunas dudas y llenar lagunas. 
En Santiago del Estero en los '60: maestra, estudiante universitaria y periodista amateur

\author{
"Era una workalcoholic. No \\ quería pensar"
}

Ana nació en Santiago del Estero. Sus abuelos paternos eran de origen sirio y los maternos, de origen italiano, inmigrantes que llegaron a fines del siglo XIX. Su madre era maestra, como buena parte de las mujeres de entonces, y su padre tenía un obraje; era la hija mayor de cuatro hermanos. El monte, el hachero y el obraje forman una trilogía inseparable, ya que los obrajes forestales fueron polos de desarrollo industrial que favorecieron el surgimiento de una clase media. En 1947 la provincia tenía 479.473 habitantes. A pocos años de nacer Ana, en 1953, Perón visitó Santiago del Estero a cuatrocientos años desde su fundación; la provincia pertenecía al peronismo periférico (Dargotz, Geretz y Cao, 2006). Ana realizó sus estudios primarios en el campo, en la localidad de Lugones, del departamento de Avellaneda; en sexto grado se trasladó con su familia a la ciudad de Santiago del Estero, una ciudad "horrible" según J. L. Borges, aunque, según el relato de Ana, escenario de experiencias festivas y dolorosas.

Como su madre, se recibió de maestra en el colegio privado católico Belén a los quince años. El fallecimiento de sus padres en 1964, cuando ella tenía dieciocho años, hizo que, junto a sus hermanos, quedaran a cargo de una tía. Trabajaría entonces como maestra para sostener sus estudios en la universidad y, también, en los medios periodísticos locales.

Transcribo sus primeros recuerdos sobre la universidad:

- Bueno, en la ciudad de Santiago del Estero me adecué como pude, rápidamente, pero bien. Entonces cursé la secundaria y no había opciones en ese momento para seguir estudiando en la universidad. No había ninguna alternativa pero, en ese momento, la gente de la UCA de acá, junto con uno de los máximos sacerdotes provinciales que tenían allá, en la Católica en Santiago, un alemán, estaba creando la carrera de Ciencias Políticas y Sociales. Inmediatamente me anoté, más que nada, porque no había otra alternativa.

\section{- Era la única facultad que había}

- Estaba la Nacional, pero creo que en ese momento únicamente se daba Ingeniería Forestal porque, más adelante, los primeros graduados de esa carrera fueron los que abrieron Sociología. Ciencias Políticas y Sociales, se llamaba. ¿O Ciencias Políticas solo? Ya no me acuerdo. Si tuviera el título... Y bueno, me anoté y me recibí en el año 1972. Di muchas, muchas materias. Era muy, muy parecida al programa de acá de Ciencias Políticas de la UCA. Eran los profesores que viajaban. Di mi última materia en el año 1971.

En 1960 se constituyó la Universidad Católica de Santiago del Estero, promovida por un grupo de laicos, con el apoyo de la Congregación Hermanos de la Misericordia; en 1968 se abrió la carrera de Ciencias Políticas y Sociales (Tasso, 2010: 13-38). El “alemán" que Ana recuerda era Bernardo Niessen, quien fue rector de la Universidad. En sus estatutos se define a la universidad como un centro de cultura superior sin fines de lucro, ligado al humanismo cristiano. Su "olvido" del nombre exacto de la carrera refiere a las contingencias de la culminación de la misma y del acceso al título, que vivieron tantos exiliados forzados en los primeros setenta, con carreras que quedaron truncas y que, en algunos casos, se retomaron al retornar al país.

De aquellos años universitarios recordó que tenían muchos profesores que viajaban, entre otros, Carlos Eroles; también a Pedro Orieta, que era santiagueño y quien fue uno de los decanos de la facultad. Tasso señala que, además de Eroles, los profesores viajeros eran Horacio Seoane, Guillermo Magrassi y Alberto Tasso; también era profesor visitante el sociólogo danés Cristian Gravenhorst.

- ¿Y qué recordás de esa experiencia universitaria, de esa formación?

- Era una formación, a ver, interesante en términos del encuadre sociológico. Como todas las carreras de Ciencias Políticas, tiene muchas materias comunes con Derecho, por ejemplo, las materias de Relaciones Internacionales. Ese tipo de materias me parecieron interesantísimas. Lo que sí recuerdo (a nivel personal te digo) era entrar igual que en la UCA con Teología.

\section{- ¿Tus padres eran religiosos?}

- Bueno, no. Mi madre era católica, mi padre era... ¿cómo se llama?

- ¿Era musulmán?

- No. La otra que tienen ellos, no me acuerdo, la otra iglesia, aunque no era practicante. Pero yo reaccionaba bastante contra esa especie de cosa muy conservadora que tenían y, en ese momento, mi inquietud era muy politizada, no sé por qué, ¿sí? Tenía amigos con los cuales dialogaba. Entonces surgió la Teología de la Liberación y yo hice una tesis sobre Camilo Torres. 
- Ah, mirá vos... No quisiera imaginarme la ciudad de Santiago del Estero en ese momento

- No, siempre había algo y me decían que yo lo hacía a propósito para escandalizar, pero fijate que, avanzada la carrera, yo empecé a buscarme becas acá, en Buenos Aires, y venía por un mes y tomaba la beca. Pero, obviamente, como el contacto eran ellos, las becas las organizaban los demócratas cristianos; pero era gente muy interesante. Ay, ¿cómo se llamaba este tipo que sé que murió hace poco? Eroles, Carlos Eroles. Él organizaba acá seminarios, por ejemplo, que eran un cruce entre Sociología y Economía, que nos venían perfecto y yo venía casi siempre por mis antecedentes o por las notas que tenía (tenía notas altas).

\section{(...)}

- Y decime, ¿por qué hiciste el trabajo sobre Camilo Torres? ¿Quién te orientó, cuando decidiste trabajar sobre ese tema...?

- Andaba buscando quién me dirigiera. Cuando se enteraron que lo iba a hacer... No, no me dirigía nadie en especial. Empecé a buscar quién me dirigiera en el tema. Yo estaba muy entusiasmada por este personaje. En esa época, ya habían pasado diez años de la Revolución Cubana, pero era siempre muy fascinante, y me parecía fascinante, tan diferente ese cura. No alcancé ni a hacerla, ni a escribir la tesis, o sea, iba haciendo por mi cuenta, nadie me quería dirigir porque les parecía que era descabellado hacer la tesis, recibirme sobre eso, ¿entendés?

Yo seguía trabada, discutiendo porque me había propuesto "no me van a ganar", "no me van a ganar", y estuve así discutiendo todo ese año para que me permitieran anotarla, al menos.

Una tesis sobre Camilo Torres podía resultar revulsiva pero no extemporánea. Cabe recordar que en Santiago del Estero nació la primera guerrilla Los Uturuncos, así como Mario Roberto Santucho, líder del ERP. En particular, uno de sus hermanos, Francisco René Santucho, había tenido una intensa actividad cultural en la ciudad de Santiago del Estero en los años cincuenta y sesenta. En esos últimos años, antes de partir a Buenos Aires, iniciaría una militancia política "de superficie" a partir de contactos políticos con el ERP.

Los estudios universitarios se combinaron entonces con el trabajo como maestra y como periodista en los medios locales.
- Mientras yo hacía la carrera, y después de que terminé, trabajaba en la televisión, en el noticiero. Apareció la televisión. Yo producía las noticias. Entonces era sencillo: ¿quién carajo va a producir noticas en Santiago del Estero? Nada. Llegaba, éramos todos en el interior filiales de Canal 13, o sea, Clarín extendió sus tentáculos en ese momento. Entonces, mandaban eso, mandaban el material fílmico, mandaban las noticias. Lo que había que hacer era reescribir. Eso hacíamos. Más teníamos el programita...

\section{- ¿Mientras estudiabas, te dedicabas a eso?}

- Sí. Menos mientras estudiaba y, de manera más intensa cuando terminé. Pero lo que hice en 1970 y 1971, fue un programa los fines de semana. Te imaginás, Santiago del Estero, me volvía loca. Tenía un novio que vivía en Córdoba entonces tenía todo el tiempo para mí. Y un programa, inventé un programa periodístico los fines de semana.

Las primeras transmisiones televisas en Santiago del Estero comenzaron en 1963, con la salida al aire de Canal 7; el primer informativo local fue conducido por Ana y Hugo Cesca, quienes recibían las cintas con las noticias envasadas desde Buenos Aires, y leían los copetes frente a las cámaras antes de proyectarlas (Picco, 2012).

En esos años, como estudiante, solía viajar a Buenos Aires para hacer seminarios, pero fue importante en particular su viaje, con una beca a Estados Unidos, a la Universidad de Harvard, a fines de 1969 durante dos meses. En ese viaje tomó un curso con Marshall McLuhan y realizó visitas a distintos lugares pero, sobre todo, hizo entrevistas a figuras como Henry Cabot Lodge, demócrata que negoció con Ho Chi Min; esas entrevistas eran luego un insumo para sus programas.

- Cuando viajaba, hacía siempre cosas para la televisión de Santiago del Estero y para mi programita del domingo (hoy mi programa del domingo).

- ¿Cómo se llamaba tu programa?

- "Nuestra tarde". Dios mío, era una loca. Vos sabés que a veces veo fotos: me ponía una peluca, pero no eran pelucas, eran apliques, esos apliques... No es que no tenía pelo. Si no, ¿qué vas a hacer en Santiago del Estero? Me quería cortar todas las venas.

\section{Pero Ana escribía también en un diario local:}

-Escribí cosas (sin haber elegido en ese momento, sin haber elegido específica o conscientemente el tema de género), escribía notas sobre abortos, sobre adopción. 
No sé por qué. Qué sé yo, porque era huérfana hablaba de la adopción. Era una enferma, una workalcoholic. Nunca paraba. No, no. Me encantaba, inventaba cada cosa... Es más, no quería pensar, evidentemente. No quería pensar.

También escribía notas con insumos que venían de su relación con gente del Ministerio de Bienestar Social y de su contacto con las editoriales de Buenos Aires que le enviaban los libros que salían; pero sobre todo escribía "para no pensar" en la muerte trágica de sus padres. Eso motivaría, además de una ruptura sentimental, su partida a Buenos Aires.

\section{En Buenos Aires: periodismo, política y amor}

\author{
"Una kamikaze total" \\ "Todo era tan intenso y tan \\ rápido".
}

Cuando se trasladó a Buenos Aires, comenzó a vivir en una casa en la que se alquilaban piezas, y conoció, entre otras personas, a María Moreno. Se vinculó entonces con el ambiente literario de Buenos Aires porque una de sus hermanas, Susana, psicoanalista, estaba casada con el periodista y escritor Norberto Soares, autor del libro Gente que baila (2013) y muy recordado por María Moreno en el libro Black out (2016), por su trabajo en La Opinión, El Cronista y Primera Plana. En ese ambiente se sentía un poco marginal porque no era escritora. Recuerda que "tenía una interlocución interesante porque todos eran muy interesantes; $y$, al mismo tiempo, -vos te imaginás- yo me sentía un sapo tan, tan de otro pozo".

Primero consiguió un trabajo como productora de una programa de música en Canal 9 (Música en libertad) y luego fue contratada en 1972 en Canal 13:

- Me contrataron en el noticiero de Telenoche. Salir todos los días era un delirio que solamente yo pude haber dicho que sí. A veces Mónica Mihanovich me encuentra y me dice "vos sos una kamikaze". Estuve un año. Una kamikaze total.

\section{- ¿Y hay grabaciones de eso en algún lado?}

-Sí, claro. Pero en el año 1972 ¿escuchás? '72. A los nueve meses de estar en el canal, al final del año van a entrevistar a Perón. Y yo y otros dos compañeros salíamos a cada rato a decir "la única entrevista exclusiva al General Perón y qué sé yo...”, pero Constancio Vigil, que estaba en ese momento dirigiendo el 13, viene y dice: "ya vi la entrevista: no, no puede ser, Perón gana en esa entrevista...” ¿Viste? porque estaba pulseando con Lanusse.

- Con Lanusse, claro.

- Y nosotros dijimos: “¿ah, sí?” y nos da la entrevista: "o la voy a editar", "no, que vaya la entrevista como está", "no" le hacíamos una pulseada. Y, entonces, llegaba Rucci, estaba invitado en ese momento en el piso para escuchar y comentar. En la mitad de todo ese forcejeo finalmente dijimos: "vamos a renunciar. Si no sale, renunciamos". Y, como el contacto, por ejemplo, con Córdoba y con Rosario, era lo que se llamaba cable...

\section{- Cable coaxial.}

- El coaxial cada segundo es carísimo, entonces lo dejamos enganchado, salimos y decimos: "bueno, la entrevista que hemos prometido no puede salir porque esto, esto, aquello" (con Vigil ahí), por supuesto, sabiendo que terminábamos y dijimos: "adiós". Seguro que nos iban a echar.

- ¿Qué edad tenías en ese momento?

- Veinticinco años, veinticinco años ya. Nos echaron. Pero los otros eran conocidos. Uno era ¿cómo se llamaba?: Julio Ricardo, que es bastante peronacho. Otro era Rousselot, me parece, era un asqueroso. Pero los otros eran muy conocidos y salieron de ahí y los tomaron en otro lado y yo empecé a boyar en Buenos Aires.

De su paso por Canal 13 recuerda que, rápidamente, el jefe del noticiero, se dio cuenta de su modo de comunicar las noticias:

- Era horrible en ese momento porque me decían que ya se habían dado cuenta de qué manera yo daba las noticias de cada, suponte, “operativo”. Decía: “los asesinos, los asesinos..." y no me lograban hacer decir la palabra "los asesinos", "el asesinato de..." o "los asesinos de...". Por lo cual, me odiaba ese tipo. Si me hubiera podido dar una piña, me la daba, pero en ese enfrentamiento, en esa tensión permanente cada día de cómo se informaba eso, cuando vos tenías un cierto modo. Bueno, pero al mismo tiempo, ahí empecé yo mis contactos con la JP.

Ese estilo de comunicar las noticias estaba ligado con su militancia política. Para entonces ya estaba vinculada con la Asociación de Periodistas de Buenos Aires (APBA) y formaría parte del Bloque Peronista de prensa, que 
era parte de la Juventud Trabajadora Peronista (JTP), el frente de masas que conducía Montoneros. Como escribe Lola Arias (Arias, 2016) a partir de los recuerdos de una de Liza, una de sus hijas, "cuando era joven, mi madre tenía dos caras. Por un lado militaba en Montoneros, y por otro, era la chica bonita que dice las noticias detrás del escritorio". La combinación entre periodismo y política fue un rasgo de la época.

Cuando en 1973 Ana comienza a trabajar en Canal 7 como periodista al aire "yo ya tenía mi núcleo y mi jefe y mi recontra jefe y otro, viste cómo era en ese momento, la JP, Montos". De esa experiencia en Canal 7 recuerda en particular la asunción de HéctorJ. Cámpora en el Teatro Colón:

-Cuando fueron las elecciones, entramos al canal. Allí trabajaba Magdalena Ruiz Guiñazú, quien, cuando iba a asumir Cámpora, era la única que tenía ropa adecuada para ir al Colón. La mandaron allí para que transmitiera mientras estábamos todos ahí. Era algo, ¿viste? enloquecido. Entonces Magdalena estaba transmitiendo y dice: "Y hace su entrada el Teniente General Lanusse", en lugar de "Cámpora".

- ¡Se le escapó!

- Y bueno, venía haciendo eso desde hace cuánto... se le re-escapó. Y, a partir de ahí, se hizo como la noche, la noche sideral, porque la cuestión era no echar a la gente. Era todo bien intencionado y Magdalena quedó a tal punto que se fue, a pasar de todo. Una vez la crucé en un cumpleaños y le dije: “¿vos te acordás de eso?”. Esa noche ahí le decíamos: “ahora seguí, seguí de cualquier manera y no te corrijas, no te corrijas, no te corrijas".

Al mismo tiempo que participaba en las transmisiones de los acontecimientos políticos locales, Canal 7 la envió a hacer programas sobre países del Tercer Mundo. Pocas mujeres podían realizar esos viajes tan largos, Ana además manejaba bien el inglés y tenía dominio de las tecnologías de la época, entonces el audicom, con el cual se filmaba primero y luego se agregaba el audio. De uno de esos viajes recordó:

-El otro día cuando murió Kadhafi pasaron una transmisión y alguien decía: “¿quién será la chica que lo entrevista acá?”. Era yo. Yo armaba dentro del programa producido por él, lo mío. O sea, de viaje armaba esto y después lo pasaba, o sea, lo editaba porque además era audicom, mientras yo filmaba (yo me iba con equipo, con fotógrafo, sonidista), entonces, mientras hacías todo eso, yo iba explicando, hablando...
Entonces hice programas en Rumania, en Libia, en Cuba, entre otros lugares, a los que fui porque había que entrevistar a Castro. Entonces lo entrevistamos yo y Alicia Raboy (que era la mamá de Ángela), la chica que en ese momento empezó la relación con Paco Urondo. Ella lo hacía para la revista Noticias (¿te acordás de Noticias de los Monto?) y para otra más. Yo no sé, mirá, cuando volví de ese viaje, volví a mi casa que había caído toda.

Ya estaba actuando la Triple A. Poco tiempo antes, como parte de su trabajo en Canal 7, Ana había conocido a Nicolás Casullo, quien para entonces era el asesor de Jorge Taiana en el Ministerio de Educación y Cultura, en el Departamento de Cultura y Comunicación, que estaba alineado con la Tendencia Revolucionaria. La habían convocado del Ministerio para armar el Canal 4 de Educación:

- El proto-Encuentro. Taiana estaba contentísimo con eso. Y yo estuve en el programa inicial que consistía en entrevistar a Taiana (yo ahí de bastonera de toda la inauguración). Y bueno, cuando se iba a inaugurar, cayó Cámpora, se cayó el proyecto. Todo ¿cuánto duró?, ¿duró un mes y medio? Todo era tan intenso y tan rápido.

- Y ahí lo conociste a Nicolás, me decías.

- Ese lugar vendría a ser una oficina de irradiación de todo. Salió la vez pasada en Página1z la síntesis de un libro que salió sobre los Huerque Mapu. Nicolás hizo el disco de Montoneros, las letras, las introducciones, todo eso, las letras con la música de los Huerques. Había una campaña para el interior sobre las vinchucas también que tenía textos, canciones. Oesterheld hacía las historietas para El Descamisado. Esta era una oficina increíble. Yo me reunía con él todos los jueves porque, bueno, te bajaban la línea de lo que había que defender, destruir, armar. Porque yo tenía un programa de radio con Norman Briski, te das cuenta que de la universidad, nada. Tenía un programa con Norman que era en Radio Belgrano, todos los días, dos horas.

En ese Departamento trabajaban, entre otros, Oscar Steimberg, Alcira Argumendo, Norman Brisky y Horacio González, y se llevarían adelante varias iniciativas como un diario para chicos, una editorial de libros accesibles, radioteatros sobre figuras latinoamericanas, además de la contratación de los Huerque Mapu, autores de la cantante sobre Montoneros y la Resistencia peronista (Smerling y Zak, 2014). Con Nicolás, comenzaron su relación sentimental en 1974 en tiempos cada vez más peligrosos. Su jefe en el Noticiero de Canal 7 le recomendó no ir más debido al peligro, y que le sostendría el 
sueldo. Dejó de ir en septiembre/octubre cuando "entró el 'lopezreguismo' de una manera brutal, brutal, brutal":

- Ya en ese momento Nicolás también dejó de ir al Ministerio, se volvió muy, muy peligroso y tuvo que salir rápidamente, del día a la noche. En el interín nos casamos. Nos casamos en noviembre, creo. Ya los quince días lo tuvieron que sacar. Tuvo que salir y fue a Cuba. Yo me quedé un tiempo más y me fui a Caracas. Mientras estaba allí, Nicolás me hablaba y me decía: "bueno, entonces, los compañeros te van a traer”.

Casarse "en el interín" (una semana antes de la partida de Nicolás) era parte de la aceleración del momento histórico y fue común en parejas militantes. La idea de irse por un tiempo para después volver coincide con otros testimonios de la época. La partida era inminente.

\section{De Venezuela a México: exilio, universidad y maternidad}

"Muchas experiencias, diferentes de cosas".

Los estudios sobre el exilio en México se distinguen entre una primera etapa del exilio, en el bienio 1974-1975, y la segunda, entre 1976 y 1979, momento en el cual un elevado porcentaje de los argentinos estuvo constituido por profesores, académicos y estudiantes, y que en el abanico de profesiones se destacaron, entre otras, la de los periodistas (Yankelevich, 2009). México fue la parada final del exilio de Ana y Nicolás, quienes partieron de la Argentina en 1974. Ambos eran periodistas y habían dejado estudios universitarios sin terminar. Recuerda la gestión de Nicolás para que fuera a Cuba: "Bueno, en esa discusión, me quedo en Caracas y él, finalmente, viene a Caracas (gano yo). A los cubanos les cayó horrible. Nos quedamos ese año ahí pensando 'ya volvemos' porque las elecciones iban a ser en septiembre".

De su experiencia en Caracas en 1974 y 1975 recuerda:

- Hice dos cosas en Caracas. Conseguí un trabajo en una agencia que se llamaba "de publicidad" (una productora, ¿viste estas productoras que hay ahora?), entonces filmaba mucho, dirigía películas de publicidades institucionales del Ministerio; yo filmé la nacionalización del petróleo en Venezuela (era un año nuevo). Después me fui incluso un mes a la selva, en el límite de Venezuela con Colombia, donde estaban los indios motilones que todavía eran aculturizados, algo impresionante en esa época. Estuve como un mes allí, con equipo, con un fotógrafo argentino que era genial.

Bueno, estaba haciendo todo eso y conocí a alguien -un argentino que hace años vive ahí-, que me dijo: "¿sabés que yo tengo todas las colecciones de todas las revistas argentinas políticas?”; “ah, mirá”; “sí, El descamisado, Noticias, Militancia (la de Ortega Peña), todas, todas, todas". "Ah - dije- ¿vos serías tan amable de, a poco, ir prestándome los números?, yo voy a filmar los títulos y las fotos". Lo convencí y, entonces, todos los sábados y domingos entrábamos (acostumbrados a la clandestinidad) en la agencia y filmábamos con las lentillas, porque hay que tener todo preparado para hacer animación. Filmaba, filmaba, filmaba. Filmé todas las colecciones.

Filmar era prolongar una experiencia política en el exilio, era recuperar parte de lo abandonado en esa partida urgente.

La alternativa de trasladarse a México surgió a partir de la visita que Nicolás realizara a ese país, por el fallecimiento de la periodista Silvia Rudni, esposa de Jorge Bernetti. Ana recordó de aquel momento:

- Entonces volvió Nicolás a Caracas y me dijo: “mirá, Ana, vamos a irnos a México porque la verdad es como que es un país en serio, no es como Caracas". Le dije: "a vos Venezuela te parece que no es seria porque no laburás", porque él no podía trabajar. Ahí escribió toda su historia del peronismo. No podía trabajar porque no podía hacerlo solo de periodista porque estaba prohibido por ley.

- O sea, era mejor lugar para vos que para Nicolás.

-Claro, pero, al mismo tiempo, es cierto que ya había cubierto toda mi cuota de filmar. Yo siempre trataba de sacar un usufructo de todo lo que encontraba. "Nos vamos a México", dijimos, porque no habían pasado las elecciones, o sea, estábamos todavía en el año 1975. Y, cuando llegamos, vivíamos con Jorge, alquilamos juntos un departamento, a él, y a Jorge le habían ofrecido la remodelación de un diario muy importante. Ese diario era El Universal, y le daban sueldos, o sea, llegamos con sueldo. Y, bueno, así es como se produjo el golpe cuando llegamos. Llegamos en febrero y en marzo fue el golpe.

Luego de esa primera etapa de convivencia con Jorge Bernetti, se instalaron en la Villa Olímpica, que fue una zona en la que residieron muchos exiliados argentinos.

Su actividad en México comprendió el trabajo en la 
filmoteca de la Universidad Nacional Autónoma de México (UNAM) y la actividad como profesora universitaria en la Universidad Autónoma Metropolitana Xochimilco (UAM). Le propuso entonces a Rodolfo Puiggros, exilado también en ese país desde 1975, que se había incorporado en 1977 al Movimiento Peronista Montonero junto con otras figuras (Puiggrós, 2010 : $p$. 214) y se desempeñaba como docente en la UNAM, hacer un convenio con la universidad mexicana para producir una película sobre Montoneros y la historia nacional. Las revistas filmadas en Caracas serían un insumo, también lo fueron para la historia del peronismo que Nicolás había comenzado a escribir en Caracas. Se firmó el convenio y durante un año se dedicó a juntar material, con el apoyo de un montajista. Se produjo la película titulada "Montoneros, crónica de una guerra de liberación", de una hora y cuarenta minutos, terminada en 1976, en el marco del Departamento de actividades cinematográficas de la UNAM y a cargo del Grupo Cine de la Resistencia. Firmó como directora con el seudónimo "Cristina Benítez", y como guionista Nicolás, como "Hernán Castillo". Ana recuerda que en el guion trabajó Nicolás Casullo con su acompañamiento, y con "compañeros que iban y venían", que en esos tránsitos caían. El negativo quedó en la filmoteca de la UNAM y, a partir de la insistencia de la Embajada, se logró sacar una copia y remasterizar imagen y sonido, y recuperar el material con la gestión de Liliana Mazure en la dirección del INCAA.

\section{Su visión de aquel documental era crítica:}

- No es gran cosa. Uno lo ve.... Pero lo interesante es el texto. Porque verdaderamente lo interesante ahí es qué se dice y cómo se dice, y cómo en una época se narra la historia argentina: está muy mal. Ahí te das cuenta cuáles eran los núcleos fuertes de los errores pero, bueno, ahí está expuesto. La historia marcha como la versión de "golpe contra golpe", siempre, desde el siglo XIX hasta ahora, hasta el golpe militar.

Según Bernetti y Giardinelli (Bernetti y Giardinelli, 2003) entre 1976 y 1979 fueron los peores años del exilio en México, signados por la gran represión y el mayor éxodo, por el "exilio de la guerrilla" y la dispersión y el repliegue de Montoneros. El documental se produjo a fines de 1976, y en 1977 ya estaba circulando. Mientras se dedicaba a ese documental, nació su primera hija. Recuerda el adelanto del parto por la magnetización de la panza, al haber estado trabajando sentada muchas horas con el sonido.

Pero durante el exilio, como en otras trayectorias, se produjo una inserción en el ámbito universitario. Continuó trabajando como periodista, escribiendo columnas de cine en el periódico Uno más uno, fundado por una cooperativa de periodistas, desde el número cero en 1977 hasta 1983, cuyo director era Manuel Becerra Acosta exsubdirector de Excelsior, que había sufrido una ofensiva por parte del gobierno por su tono crítico y provocador. En el nuevo diario no escribían muchas mujeres, entre otras Ana María Amado, María Seoane y Elena Poniatoswka. En sus columnas sobre cine, Ana informaba sobre la censura y algunas nuevas figuras del cine argentino (Basso, 2016). Fue parte también del Consejo de redacción de Imágenes, publicación especializada en cine y cultura.

En México comenzaría lo que definió como su "etapa académica", a partir de su amistad con Héctor "Toto" Schmucler. Schmucler había sido contratado en la UAM apenas arribó a México, a partir de la mediación de Armand Mattelart, con quien dirigía la revista Comunicación y Cultura, y era el primer director de la carrera de Comunicación (Zarowsky, 2015: 127-160). Su esposa, Ana María "Menena" Nethol, la convocó en 1979 como auxiliar de cátedra en la UAM en la asignatura Semiología. La universidad fue creada en 1974 ante el crecimiento de la demanda estudiantil en la zona metropolitana y estaba organizada en divisiones y departamentos. También se sumaría al comité editorial de la revista.

A diferencia de otros exiliados, Ana no pudo realizar estudios de posgrado porque no había podido terminar su tesis de licenciatura y recibirse; desde México, realizó gestiones para enviarla pero resultó imposible, incluso pensó en volver para concretarlo. Cuando se produjo el retorno a la Argentina de Nethol, quedó a cargo en la UNAM de las cátedras de Semiología I y Semiología II. De esa experiencia recuerda que había sistemas modulares, que tenía grupos de veinte o veinticinco estudiantes que se sentaban en círculo en las aulas y que tenía una interlocución y transmisión más serena, comparando con la experiencia masiva de Filosofía y Letras. Siguió en contacto con la crítica cinematográfica y con la escritura.

Su otra inserción fue como investigadora del Instituto Latinoamericano de Estudios Transnacionales (ILET), donde participa en investigaciones sobre mujeres de comunidades indígenas. A partir de esa inserción tomó contacto con el feminismo local. El tipo de investigación consistía en conversar con las mujeres sobre sus experiencias de trabajo, investigación que dará lugar a su tesis de grado pendiente. Se vinculó entonces con investigadoras chilenas y mexicanas feministas.

\section{Recuerda:}

-Durante todo ese tiempo, de a poquito, me fui metiendo en el feminismo local, al principio las miraba 
a las feministas con desdén, "son pequeño-burguesas", como decíamos acá, las pequeño-burguesas que ahora descubren que son mujeres. Después no, trabajaba con ellas, escribía para las revistas feministas.

Mi tesis de grado. Cuando volví, lo primero que hice, fue eso. A ver, porque como volvíamos sin un mango hasta para pagarnos los pasajes de vuelta. Fuimos los primeros que volvimos por el enfermo de Nicolás que decía: "allá va a haber elecciones, va a haber".

- ¿En qué año volvieron?

- ¡A principio del ' 83 ! Cuando se abría la campaña, se abría la campaña acá de la política. Entonces Nicolás decía que se le paraba el corazón si no participaba de esto.

La tesis tuvo por título "El discurso femenino como comunicación alternativa" y fue presentada al volver a la Argentina (23/12/1987), dirigida por Schmukler.

La decisión de volver generó nuevas diferencias en la pareja. Los artículos publicados en 1982 en la revista Controversia por Nicolás Casullo y Sergio Caletti giran en torno a la campaña política en la Argentina y la vuelta al país (Carli, 2014). Cabe recordar que en 1981 se había conformado la Multipartidaria y, entre 1981 y 1982, se habían producido las primeras liberaciones de presos políticos; la guerra de Malvinas estallaría en 1982. Mientras los hombres estaban deseosos de volver, Ana seguramente, como otras mujeres, pensaba en las contingencias de esa vuelta y en la escolaridad de las hijas.

\section{El retorno a Buenos Aires: feminismo, universidad y escritura}

\author{
"Cuando volví, todo eso \\ siguió así. La universidad, \\ la escritura y la \\ investigación" \\ "un aprendizaje a full"
}

Cuando retornaron a la Argentina, se instalaron en un departamento en Once y buscaron escuela para sus hijas que tenían seis y dos años. Quedó sorprendida por las escuelas y las directoras, en comparación con la experiencia en México. Su hija Mariana había asistido a la escuela privada Escuela Emilio Almendros del Distrito Federal. En México, las escuelas públicas tenían un nivel inferior que las argentinas, por lo cual los exilados habían optado en su mayoría por la escuela privada progresista (Bernetti y Giardinelli, 2003). En la Argentina, mientras tanto, el sistema educativo público había sufrido el impacto de la dictadura militar, que se manifestó en estrategias represivas y de disciplinamiento cotidiano, el avance de la tecnocracia y la homogenización didáctica (Pineau, 2006).

\section{Recuerda la situación de su hija Mariana:}

- Ella, la más grande, había estado desde los cuatro años en lugares de México (lo privado, bueno, lo privado y lo estatal también). Son escuelas tan activistas, son muy activas, progresistas, muy progresistas. Acá era así: no se podía usar pantalón todavía, iescuchame!, eran de las Guardias Rojas (de la dura) en las escuelas. Fuimos al Lengüitas. La del Lengüitas nos miraba así... Yo le decía a Nicolás, "vámonos". Además del terror que te daba en ese momento. Todavía estaba la dictadura. La escuela normal era la más pasable. La Número 1.

Comenzó a trabajar como periodista en la editorial Perfil, que había sido creada en 1976, y en la revista Somos de la editorial Atlántida, inicialmente como secretaria de redacción de la sección política, y solicitó luego pasar a la sección Mujer. Recuerda aquella etapa como abrumadora y complicada para la vida familiar, por la intensidad del trabajo periodístico. Luego de que la indemnizarany, gracias a la colaboración de Alicia Entel, a quien había conocido en el ILET y que para entonces dirigía la revista Vivir de la editorial Abril, trabajó para la revista durante 1983 y 1984. En aquella época, se desempeñó también como investigadora del ILET, donde Nicolás era director, junto con Alcira Argumedo. Fue directora entre 1987 y 1990 del Departamento Mujer y sociedad. Coincidió allí con Susana Checa, con quien realizaron investigaciones sobre género. Retomo entonces su interés por el feminismo: "Ahí empecé a investigar a las chicas, a las mujeres de la UDA", luego publicó con Checa la investigación sobre "Participación sindical femenina en el Sindicato Gráfico (Amado y Checa, 1990).

Pero una experiencia muy importante fue, en primer lugar, su vinculación con FEMPRES (Red alternativa de Prensa femenina en América Latina), que fue creada por mujeres chilenas que volvieron a su país en 1989, y en segundo lugar, su actuación como corresponsal en Argentina.

\section{Ana recuerda:}

- FEMPRESS era una especie de folleto, de revista en la que una corresponsal por cada país latinoamericano escribía la situación más fuerte de género que había pasado. Luego, eso era distribuido a los diarios, aquí 
lo levantaban, podían levantar, por ejemplo, allá lo que mandaba yo de Argentina.

Qué retardado todo. ilmaginá!. Pero eran buenos artículos. Eso, una vez por mes. Te das cuenta que esta situación se terminó recién en el 1999/2000 porque ya las redes empezaban a ser fuertes.

Uno de los resultados de ese trabajo fue la publicación en 1996 del libro El ABC de un periodismo no sexista, a pedido del ILET, que quería relevar qué experiencias había en distintos países. Fue escrito junto a una amiga mexicana, Berta Hiriart, (del FEM) y Norma Valle, de Puerto Rico (Amado, Hiriart y Valle, 1996). Mientras las coautoras tenían experiencia de trabajo con mujeres en talleres, ella recuperó su experiencia en el periodismo grafico:

- Yo describía lo que era la televisión acá. Por ejemplo, un estilo progresista pero canchero mal, como el de Página12, que hablaba: "preso porque le tocaron una teta”, porque se hacían los cancheros todavía. Mal. Y trataba de analizar. Lo mío es lo más light del libro porque es lectura y, a veces, es divertido, lo de ellas se relaciona más con explicar cosas a tomar en cuenta para que no sea sexista.

Desde los años '9o en adelante, publicó artículos en el Suplemento de Cultura y Nación del diario Clarín y en el diario Página 12.

Su inserción en la Facultad de Filosofía y Letras se produjo en la carrera de Artes. Participó primero como ayudante de Rafael Filipelli y dictó las primeras materias de Cine. Luego, concursó como profesora adjunta de la materia Análisis y crítica cinematográfica, de la orientación Combinada, cuyo profesor titular era Claudio España. Estaba interesada en Estética y Teoría, pero desistió de presentarse también a ese concurso.

- Después, cuando pasé allá, (a Puan) seguí y, a los tres o cuatro años se planteó el tema de la dirección de la Carrera. Imaginate esa carrera, en la que, por ejemplo, la gente de Plástica miraba a todos los de cine como si fueran piojos asquerosos .Ahora ya son mayores, la nueva gente genial. Era un momento de gran tensión: por un lado, institucional y en términos de prestigio y legitimaciones internas; y por otro, política. Entonces yo entré por un acuerdo con los radicales (yo de radical nunca tuve ni un pelo), pero bueno, entré en una mayoría medio rara. Durante el segundo año de ejercer como directora de la carrera me pidieron que forme parte del claustro de profesores, del Consejo Directivo.

Ana fue directora de la carrera entre 1990 y 1996, reelegida en tres ocasiones. La etapa corresponde a los decanatos de Luis Yanes (1990-1998), que se caracterizó por ser una etapa de transición entre la recuperación democrática, signada por la normalización, y el desarrollo de transformaciones académicas vinculadas en particular con la investigación:

- O sea que de esa etapa anterior de combinación entre el periodismo, universidad y varias cosas más, pasaste a estar casi full time en la universidad.

- Nada más entre el '90 y el '96. A partir del '92 las dos cosas: Consejo Directivo más carrera, con lo cual, tuve una inmersión recontra a full en lo que sería la vida académica. De esa facultad, con esas tensiones. Por lo tanto, hoy me puteo porque me perdí la adolescencia de mi hija menor ¿no? A veces, ¿no te pasa?

- Sí.

- “A ver acá, acá, ¿cómo me jugué por esa intensidad y no por esto?”.

- Pero son difíciles las evaluaciones retrospectivas, complicadas.

- Sin duda. Bueno, la inmersión en el Consejo Directivo es un aprendizaje a full, brutal. En esta facultad sobre todo, es decir, conocés todo sobre ocho, nueve carreras, lo cual es infernal.

La autoculpabilización por la dedicación excesiva al trabajo y el descuido de la maternidad es recurrente en mujeres académicas (Carli, 2016: 81-90). Las tensiones vinculadas con el uso del tiempo se vinculan con la participación de las mujeres en ámbitos contrapuestos, público y doméstico, y las dificultades para "gerenciarlo" (Barrancos, 2012).

Durante ese período, se produjo la creación del Área Interdisciplinaria de Estudios de Género (AIEM), a partir de una iniciativa conjunta de profesoras de Artes, Antropología, Educación, Filosofía, Historia, Lenguas Clásicas y Letras. El Área tuvo primero una coordinación grupal en la que participó Ana, por Artes, junto con Mirta Barbieri, por Antropología, Margarita Roulet, por Filosofía, Marcela Nari y Susana Murphy, por Historia, Graciela Morgade, por Educación y Nora Domínguez, por Letras. En 1995 salió el primer número de la Revista Mora y fue miembro del Consejo de Redacción desde entonces. EI Área se convertiría en 1997 en Instituto.

En el Área se radicaría su primer proyecto UBACYT (1995-1998), co-dirigido por Nora Domínguez y conformado por "un equipo mixto" compuesto por graduados 
de Letras y de Artes, pero también de Sociales, como en el caso de la socióloga Alejandra Oberti. Tuvo por título "Construcciones y narraciones de género en cine, literatura y prensa escrita". Recuerda su encuentro con Nora:

- Nora se acercó a decirme: “¿vos no quisieras que armáramos un congreso de género?, porque leí tus cosas, me interesa lo que pensás...”. Ella es de Letras. Era el año 1992, entonces nos acercamos a Panesi. Le dije: “Artes y Letras ¿podemos armar un congreso?”. "Sí - dijo Panesi- me encanta”. Ahí empezamos a trabajar junto con Nora, desde ese año, el '92. Y, bueno, fue ese libro el primero del equipo. Ahora estamos armando otro, junto con Memoria Abierta.

El primer libro del equipo fue Lazos de familia. Herencias, cuerpos, ficciones, editado por Paidós en el año 2004.

- El primer producto del equipo, sí. Que fue un poco demorado porque las publicaciones suelen demorarse, ¿no?

- Pero es un libro muy elaborado. Demorado pero muy elaborado...

- ¿Te parece?

- Sí.

- Sí. Muy citado, porque me acuerdo que Nora me decía: “yo no le encuentro, no le encuentro el...". "Sí -le dije- por acá, por acá...”. Porque en ese momento era muy difícil, a ver, terminar de advertir cómo se estaba articulando el concepto de familia en términos simbólicos en este país (Amado y Domínguez, 2004).

- Cuando trabajaste en la revista Vivir ¿ahí hubo una primera conexión con lo familiar?

- Sí, puede ser. Mirá, nunca se me había ocurrido hacer esa conexión.

- Porque imagino debés haber escrito notas sobre padres, niños, crianza, en esa revista.

- Sí, sí. Dar la teta. Cualquier cosa escribía pero en esa línea. Lo otro era ya razonar desde una perspectiva más de lazos ¿no? En este caso, lazos entre reales, biológicos y simbólicos. Le dimos mucha vuelta.

Dicta seminarios en Estados Unidos, en la Universidad de Duke y de Nueva York, a partir del año 2001.

Desde entonces, sus investigaciones y publicaciones rondarían en torno a temas recurrentes: cine, política, memoria, género. Publicaría artículos en revistas académicas y culturales, y formaría parte del Comité editorial de otra (Mora y Confines). Ganó la beca Guggenheim 2010-2011 por estudios literarios. Un año antes publicó en La imagen justa. Cine argentino y política 1980-2007 (Amado,2009), producto de su tesis doctoral en Humanidades en la Universidad de Leiden, en Holanda, mientras era su directora Luz Rodríguez Carranza, también una exilada argentina graduada de la Universidad Nacional de Córdoba, que no retornó al país. Los lazos del exilio se extienden en el tiempo y no tienen fronteras.

En el campo de las humanidades y las ciencias sociales ha ido ganando relevancia cada vez la cuestión de la imagen, pero el interés de Ana por el cine era de larga data:

- ¿Pero antes tenías ese interés en los '70 o fue más durante el exilio?

- Me encantaba, era fascinante pero era como si hubiera nacido con el interés. Era fanática. Yo iba sola al cine desde que era adolescente, a los cines de Santiago del Estero. Qué bien la pregunta, si no me lo decías...Cada tanto yo me acuerdo: ¿cómo es que yo pude haber apreciado de ese manera la película de Godard?, ¿cuántos años tenía que me fui a tal cine y yo me encontraba deslumbrada por esa manera de narrar, que era tan diferente a todas; y que volvía al día siguiente y volvía al día siguiente? No me puedo acordar. La película es del año 1960, así que yo debo tener...

- ¿La habrás visto en Santiago del Estero en qué año?

- 1962, o sea que tenía quince años, dieciséis.

-¿Qué había? ¿Un cine arte, un cine club, un cine común?

- ¡No! Pasaban lo que mandaban. Pasaban lo que mandaban, desde la de Isabel Sarli, a esto. Yo veía todo, todo. Era medio una enferma de leer y ver cine.

Si el cine era la pasión de Ana, la afición por la lectura y la escritura era compartida por Ana y Nicolás, como sucede en muchas parejas vinculadas con las humanidades y las ciencias sociales:

- Mirá, teníamos una enorme independencia hacia los campos ¿sí? Pero relativa en términos de insumos culturales o de lectura. Cuando volvimos, él también se empezó a insertar desde una perspectiva como más filosófica, si se quiere. Lo mío siempre fue un poco más literario. Teníamos cada quien nuestra biblioteca. Mi casa es pura biblioteca. Pero teníamos áreas 
comunes de Estética. Y, después de las producciones, yo era muy independiente. No le decía: "me leés esto", pero él siempre me lo pedía. Teníamos la costumbre de que yo leyera lo que iba escribiendo, señalando "esto sí, esto no", discutiéndole.

- Pero no al revés.

- Yo me acostumbré. Porque él siempre encontraba todo bien, por lo cual, a mí ese tipo de lectores no me interesan, no me interesaba.

- Y quizás porque tu escritura... A mí me llamó la atención tu escritura. Yo no te había leído y es una escritura muy agradable, muy densa pero muy leíble al mismo tiempo. Me quedé pensando cómo era la conexión entre la escritura periodística y la escritura académica. El salto de un estilo al otro, ¿no?
- Cuesta a veces eso también. Pero soy un poco más clara que Nicolás porque él es más denso. Tiene una escritura para cualquier cosa, que es barroca y de matriz literaria, aun escribiendo sobre política, sobre cualquier cosa. Entonces yo tengo las frases un poco más directas. Al principio, como que le discutía un poco. Él, cuando me leía a mí, me decía: “está muy bien". Punto. Y yo no quería eso, sino que quería saber sobre qué puntos debería trabajar. En cambio, cuando yo lo leía a él, no. Cuando me das a leer, si me das a leer, opino. Entonces me decía: "no te lo doy como jefa de redacción. Basta con el espíritu de jefa de redacción: no me corrijas".

La escritura abierta de Ana contrastaba con la escritura barroca de Nicolás; el desplazamiento por distintos ámbitos con diversos roles e interlocutores y el trabajo con distintos géneros, dejaron huellas en su modo de comunicarse y en las formas de la escritura.

En Ana coexistían la periodista, la militante política, la profesora universitaria, la investigadora, la activista feminista, la crítica cultural. La combinación de oficios adquiridos tempranamente como el de periodista, con el desarrollo de la profesión académica, iniciada en México y profundizada en Argentina en distintas áreas de actuación (enseñanza, investigación y gestión universitaria), trazan un itinerario singular. Aproximarnos a su itinerario biográfico, recuperando su memoria dispersa pero aguda, no exenta de humor y complicidad, permite prolongar la conversación y comprender los avatares de la historia reciente de la Argentina. 


\section{Q Referencias bibliográficas:}

»Arias, L. (2016). Mi vida después y otros textos. Buenos Aires, Reservoir Books.

»Barrancos, D. (2012). “Género y tiempo". En Domínguez Mon, A.; Mendes Diz, A.; Schwarz, P. y Camejo, M. (Comps.) (2012). Usos del tiempo, temporalidades y géneros en contextos. Buenos Aires, Antropofagia.

"Basso, M. F. (2016). Volver a entrar saltando: Memorias visuales de la segunda generación de exiliados políticos en México. Tesis para optar por el grado de Magíster en Historia y Memoria. Universidad Nacional de La Plata, Facultad de Humanidades y Ciencias de la Educación.

"Bernetti, J. L. y Giardinelli, M. (2003). México: el exilio que hemos vivido. Memoria del exilio argentino en México durante la dictadura 1976-1983. Bernal, Universidad Nacional de Quilmes.

"Carli, S. (2014). "El viaje de conocimiento en las humanidades y las ciencias sociales. Un estudio de caso sobre profesores universitarios en la Argentina durante la segunda mitad del siglo XX". En Historia de la Educación. Anuario. Vol 14, No. 2. 2013. Disponible en <http://ppct.caicyt.gov.ar/index.php/anuario/issue/view/213/showToc>.

» - (2016). “Deconstruir la profesión académica: tendencias globales y figuras históricas. Una exploración de las biografías académicas de profesoras universitarias". En Revista Propuesta Educativa. No. 45. FLACSO. ISSN: 1995-7785 pp. 81-90.

"Dargoltz, R.;Gerez, O. y Cao, H. (2006). El nuevo santiagueñazo: cambio político y régimen caudillista. Buenos Aires, Biblos.

"Navarro, A. (2017). Historia universal de Santiago del Estero. Buenos Aires, Editorial Nudista.

»Picco, E. (2012). Medios, política y poder en Santiago del Estero. 1859-2012. Santiago del Estero, Ediciones INDES.
"Pineau, P. (2006). “Impactos de un asueto educacional; las políticas educativas de la dictadura (1976-1983). En Pineau, P.; Mariño, M.; Arata, N. y Mercado, B., El principio del fin. Políticas y memorias de la educación en la última dictadura militar (1976-1983). Buenos Aires, Colihue.

»Puiggrós, A. (2010). Rodolfo Puiggrós. Retrato familiar de un intelectual militante (p. 214). Buenos Aires, Taurus.

» Smerling, T. y Zak, A. (2014). Un fusil y una canción. Buenos Aires, Planeta.

" Tasso, A. (2010). "Pensamiento social y ciencias sociales en Santiago del Estero. Autores, obras y temas (1875-1975)". En Revista Cifra No. 5, Versión digital pp. 13-38, 2010.

"Yankelevich, P. (2009). Ráfagas de un exilio. Argentinos en México, 1974-1975. México, Fondo de Cultura Económica.

»Zarowsky, M. (2015). “Del exilio a los nuevos paradigmas: los intelectuales argentinos de la comunicación en México (de Controversia a Comunicación y Cultura)". Comunicación y sociedad, Vol. 24 pp. 127-16o.

\section{Obras de Ana María Amado citadas:}

"Amado, A.y Checa, S. (1990). Participación sindical femenina en el Sindicato Docente, Vol. 2. Buenos Aires, ILET.

"Amado, A.; Hiriart, B. y Valle, N. (1996). Espacio para la igualdad. El $A B C$ de un periodismo no sexista. Santiago de Chile, Editorial Fempress.

"Amado, A. y Domínguez, N. (Comp.) (2004). Lazos de Familia. Herencias, cuerpos, ficciones. Buenos Aires, Editorial Paidós.

》Amado, A. (2009). La imagen justa. Cine argentino y política (1980-2007). Buenos Aires, Colihue. 
